\title{
The Short- and Long-Term Effect of Liraglutide on the Beta Cell Function in Type 2 Diabetic Patients
}

\author{
Toshinobu Suzuki*, Koichi Hirai, Yingchao Chen, Kunihiko Hashimoto \\ Division of Diabetes and Endocrinology, Department of Internal Medicine, NTT West Osaka Hospital, Osaka, Japan

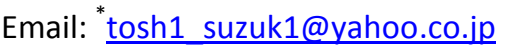

Received 22 August 2014; revised 18 September 2014; accepted 15 October 2014

Academic Editor: Masayuki Hosoi, Osaka City General Hospital, Japan

Copyright (C) 2014 by authors and Scientific Research Publishing Inc.

This work is licensed under the Creative Commons Attribution International License (CC BY).

http://creativecommons.org/licenses/by/4.0/

(c) (i) Open Access

\section{Abstract}

Glucagon-like peptide 1 (GLP-1) is a hormone, inducing glucose-dependent stimulation of insulin secretion from beta cells. Liraglutide acts as a GLP-1 receptor agonist. To assess the effect of liraglutide on the beta cell function, we performed oral glucose tolerance tests in 7 subjects with type 2 diabetes before and after treatment of liraglutide. Moreover, we performed same study again in 4 subjects at 6 months after induction. Liraglutide significantly increased area under the Curve (AUC) of plasma insulin level after glucose loading and significantly decreased AUC of plasma glucose level, compared with before induction. HOMA-beta was significantly increased, whereas insulinogenic index was not changed. HOMA-R was not affected but Matsuda index was significantly decreased after induction of liraglutide. Disposition index was not altered significantly, but tendency of improvement was observed. Glucose tolerance tests revealed that those effects of liraglutide were continued for 6 months after induction. These results showed that treatment of liraglutide could improve insulin secretion but early phase of insulin secretion was not improved. The results suggest that liraglutide is likely to improve beta-cell function, but this effect is still inadequate by six-month treatment.

\section{Keywords}

Glucagon-Like Peptide 1, Oral Glucose Tolerance Test, Insulin Secretion, Insulin Sensitivity, Type 2 Diabetes

\footnotetext{
${ }^{*}$ Corresponding author.
}

How to cite this paper: Suzuki, T., Hirai, K., Chen, Y.C. and Hashimoto, K. (2014) The Short- and Long-Term Effect of Liraglutide on the Beta Cell Function in Type 2 Diabetic Patients. Journal of Diabetes Mellitus, 4, 334-340. 


\section{Introduction}

Since incretin mimetic drugs were available for the treatment of type 2 diabetes these drugs were widely used because of its hypoglycemic effect and safety. The effect of these drugs is considered to mainly result from the actions of glucagon-like peptide-1 (GLP-1).

GLP-1 is secreted from L cells in the lower small intestine in response to ingested nutrients and stimulates insulin secretion from pancreatic $\beta$ cells depending on the blood glucose concentration [1]. GLP-1 is also physiologically active in other ways including central appetite suppression [2] [3] to improve glucose tolerance. Since GLP-1 is decomposed by DPP-4, it stays in the blood with a half-life of only several minutes. Therefore, GLP-1 itself would not be an effective drug. However, liraglutide, which is a GLP-1 receptor agonist resistant to DPP-4, was developed using one amino acid substitution and fatty acid addition and found to produce a sufficient therapeutic effect with only one injection per day [4]. The GLP-1 receptor agonist not only improves blood glucose, but also was suggested to restore $\beta$ cell function by relieving oxidation stress on $\beta$ cells in diabetic mice [5]. However, there was slightly evidence for the restoration of $\beta$ cell function by the GLP-1 receptor agonist in human [6].

Therefore, we conducted short-term and long-term assessments of changes in $\beta$ cell function by liraglutide use in patients with type 2 diabetes.

\section{Patients and Methods}

Seven patients with type 2 diabetes for 41 to 74 years of age participated in the study. All subjects were Japanese and were recruited at NTT West Osaka Hospital during admission between from June 2011 to March 2012. From the limitations of current methods of treatment or spontaneously, all of the patients, chose the new treatment by liraglutide. Participants were excluded if they had severe liver and kidney disease or exhausted endogenous insulin secretion. These patients were first withdrawn from any previous drugs, admitted, and then placed on the basal bolus insulin therapy. Endogenous insulin secretion was assessed by a $\mathrm{C}$ peptide concentration of the patients' urine. After the patients' insulin dose was minimized and their blood glucose concentration was stabilized for several days, liraglutide was newly introduced by once a daily subcutaneous injection substituted for insulin therapy. To assess $\beta$ cell function, a 75-g oral glucose tolerance test was performed twice, first immediately before the initiation of liraglutide therapy and second immediately after increasing the dose to 0.9 mg (on Day 10) of liraglutide. The area under the curve (AUC) of blood glucose level and of insulin level was evaluated. Potency of insulin secretion was assessed using the insulinogenic index and homeostasis model assessment for $\beta$ cells (HOMA- $\beta$ ); insulin resistance was assessed using homeostasis model assessment for insulin resistance (HOMA-R) and the Matsuda index; and $\beta$-cell function was assessed using disposition index. In 4 patients, a 75-g oral glucose tolerance test was performed approximately 6 months after the first test to evaluate any long-term changes, and the same parameters were determined. Hemoglobin A 1c (HbA1c) was expressed according to the value by the National Glycohemoglobin Standardization Program (NGSP).

A standard oral glucose tolerance test was performed with a 75-g glucose load after an overnight fast. Blood samples were obtained at baseline and 30, 60, 90, and 120 min after glucose load.

HOMA-R was calculated as follows: HOMA-R $=$ (fasting insulin $\times$ fasting glucose)/22.5. HOMA- $\beta$ was calculated as follows: HOMA- $\beta=(20 \times$ fasting insulin $) /($ fasting glucose -3.5$)$. Insulinogenic index was defined as the ratio of the increment of plasma insulin to that of plasma glucose at $30 \mathrm{~min}$ after the glucose load. Matsuda index was calculated by the method of Matsuda and DeFronzo as previously described [7]. Disposition index was calculated as previously described [8].

Data were represented as mean (SD). For the statistical analyses, paired $t$-tests were used for between-group comparison in the results before and after dosing changes with a $p$-value $<0.05$ as statistically significant level.

This study was approved by the Institutional Review Board Committee of NTT West Osaka Hospital, and all patients consented to participation in this study.

\section{Results}

In our 7 patients with type 2 diabetes without depletion of endogenous insulin secretion, liraglutide was newly introduced after improving glycemic control. Table 1 shows the clinical findings for each patient. All patients weighed more than the standard weight, and the duration of illness was over 10 years, except for 1 patient. Figure 1 shows the results of the 75-g oral glucose tolerance test before and at 10 days after introduction of liraglu- 
(a)

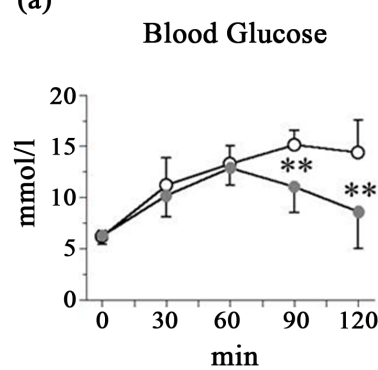

(c)

Blood Glucose (AUC)

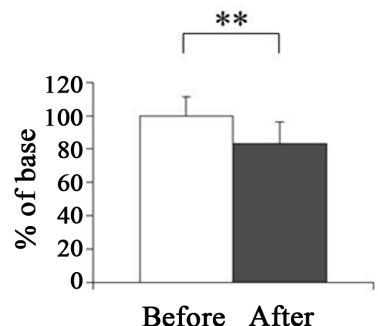

(b)

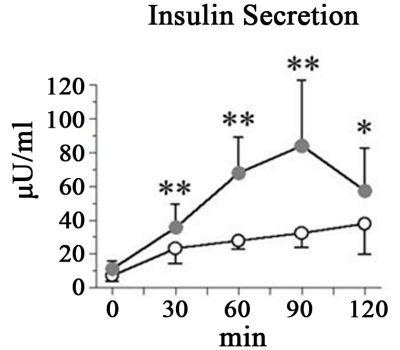

(d)

$$
\text { Insulin Secretion (AUC) }
$$

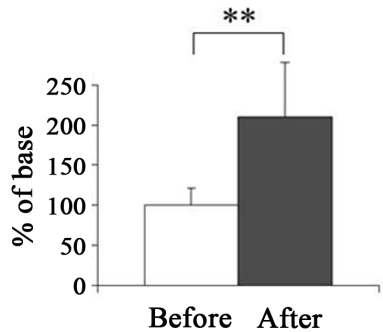

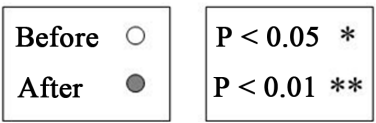

Figure 1. Treatment with Liraglutide improved glucose-stimulated insulin secretion (GSIS). (a)-(d): Blood glucose ((a) and (c)) and plasma insulin ((b) and (d)) levels during $75 \mathrm{~g}$ oral glucose tolerance tests performed on before (open circles; $\mathrm{n}=7$ ) and 10 days after treatment with Liraglutide (dose had been increased to $0.9 \mathrm{mg} /$ day) (closed circles; $\mathrm{n}=7$ ). Data are presented as percentages of the AUC of before treatment in (b) and (d). ${ }^{*} \mathrm{p}<0.05{ }^{* *} \mathrm{p}<$ 0.01 vs. before treatment assessed by paired $t$ test. Data are presented as mean (SD).

Table 1. Baseline patient profiles. Data are presented as mean (SD).

\begin{tabular}{|c|c|c|c|c|c|c|c|c|}
\hline & Case 1 & Case 2 & Case 3 & Case 4 & Case 5 & Case 6 & Case 7 & Ave. \\
\hline Age (Years) & 74 & 70 & 62 & 71 & 45 & 41 & 41 & 57.7 (13.7) \\
\hline Sex & M & M & M & M & M & M & F & \\
\hline BMI $\left(\mathrm{kg} / \mathrm{m}^{2}\right)$ & 22.5 & 24.5 & 31.9 & 32.8 & 24.5 & 33.0 & 28.9 & $28.3(4.1)$ \\
\hline $\begin{array}{l}\text { Duration } \\
\text { (Years) }\end{array}$ & 10 & 30 & 20 & 10 & 2 & 10 & 10 & $13.1(8.4)$ \\
\hline HbA1c (\%) & 6.8 & 7.1 & 7.0 & 8.9 & 7.2 & 10.5 & 9.9 & $8.2(1.4)$ \\
\hline $\begin{array}{l}\text { Urine-CRP } \\
\text { ( } \mu \mathrm{g} / \text { day) }\end{array}$ & 28 & 48 & 31 & 24 & 53 & 103 & 39 & $46.5(25.0)$ \\
\hline Therapy & $\begin{array}{l}\text { Intensive } \\
20 \mathrm{u} / \text { day }\end{array}$ & $\begin{array}{l}\text { Ultra-long } \\
6 \mathrm{u} / \text { day }\end{array}$ & $\begin{array}{l}\text { Ultra-long } \\
10 \mathrm{u} / \text { day }\end{array}$ & OHA & $\begin{array}{l}\text { Premixed } \\
28 \mathrm{u} / \text { day }\end{array}$ & $\begin{array}{l}\text { Premixed } \\
80 \text { u/day }\end{array}$ & OHA & \\
\hline
\end{tabular}

tide. Blood glucose concentrations (mmol/L) at 90 minutes and 120 minutes after loading significantly decreased (90 minutes: 15.09 [SD 1.45] vs. 11.05 [SD 2.53], p < 0.01, 120 minutes: 14.40 [SD 3.16] vs. 8.60 [SD 3.57], $\mathrm{p}<0.01$ ) (Figure 1(a)), and the AUC for blood glucose concentration significantly decreased after loading (100 [SD 11.33] vs. 83.27 [SD 13.01], p < 0.01) (Figure 1(c)), which indicated blood tolerance level improved after liraglutide use. After glucose loading, insulin level $(\mu \mathrm{U} / \mathrm{ml})$ was significantly elevated (30 minutes: 23.25 [SD 9.08] vs. 35.70 [SD 13.48], p < 0.01, 60 minutes: 27.60 [SD 4.66] vs. 68.03 [SD 21.06], p < 0.01, 90 
minutes: 32.17 [SD 8.65] vs. 83.81 [SD 38.55], p < 0.01, 120 minutes: 37.61 [SD 17.86] vs. 57.28 [SD 25.23], p $<0.05$ ) (Figure 1(b)) and the AUC for insulin level significantly increased (100 [SD 21.64] vs. 210.45 [SD 67.25], $\mathrm{p}<0.01$ ) (Figure 1(d)), which showed restoration of insulin secretion. Glucose tolerance level improved and insulin secretion was restored at 6 months after the start of liraglutide therapy, but improvements were not significant immediately after liraglutide was introduced (Figure 2(a) and Figure 2(b)). The improvement of insulin secretion was confirmed by a significant increase in HOMA- $\beta$ (50.57 [SD 13.69] vs. 86.91 [SD 28.84], p < 0.05 ) (Figure 3(a)), while the insulinogenic index showed that early secretion tended to increase (0.18 [SD 0.06 ] vs. 0.37 [SD 0.26]), but not significantly (Figure 3(b)).

No significant changes were observed according to HOMA-R (2.05 [SD 1.09] vs. 3.26 [SD 1.54]) (Figure 4(a)). The Matsuda index, which represents systemic insulin sensitivity, significantly decreased (5.27 [SD 1.98] vs. 3.13 [SD 1.15], $\mathrm{p}<0.05$ ) (Figure 4(b)). $\beta$ cell function corrected by insulin sensitivity was represented by the disposition index, and this tended to increase (1.00 [SD 0.61] vs. 1.37 [SD 1.50]), but not significantly (Figure $4(\mathrm{c})$ ).

(a)

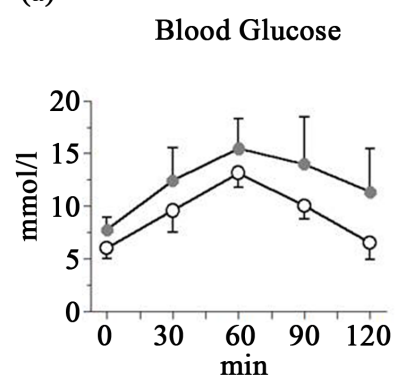

(b)

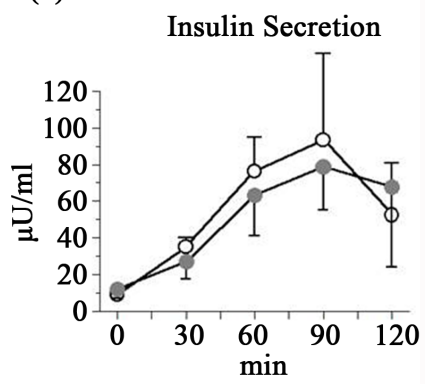

10 days after
6 months after

Figure 2. Liraglutide induced enhancement of GSIS was kept for 6 months. A-B: Blood glucose (a) and plasma insulin (b) levels during $75 \mathrm{~g}$ oral glucose tolerance tests performed on 10 days (open circles; $n=4$ ) and 6 months after treatment with Liraglutide (dose was $0.9 \mathrm{mg} /$ day) (closed circles; $n=4$ ). ${ }^{*} \mathrm{p}<$ $0.05 ;{ }^{* *} \mathrm{p}<0.01$ vs. 10 days after treatment assessed by paired $t$ test. Data are presented as mean (SD).

(a)

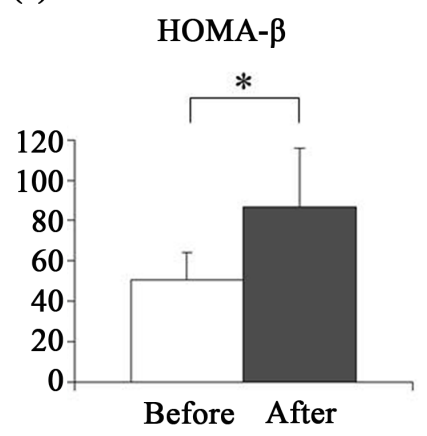

(b)

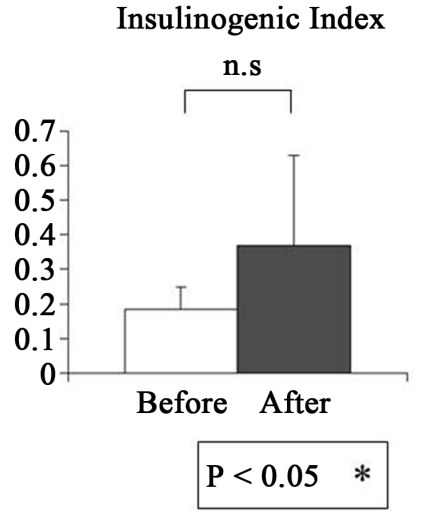

Figure 3. Liraglutide improved $\beta$ cell capacity for insulin secretion. a-b: HOMA- $\beta$ (a) and insulinogenic index (b) were calculated from the result of $75 \mathrm{~g}$ oral glucose tolerance tests performed on before (open bars; $\mathrm{n}=7$ ) and 10 days after treatment with Liraglutide (dose had been increased to $0.9 \mathrm{mg}$ / day) (closed bars; $n=7$ ). ${ }^{*} \mathrm{p}<0.05 ;{ }^{* *} \mathrm{p}<0.01$ vs. before treatment assessed by paired $t$ test. Data are presented as mean (SD). 
(a)

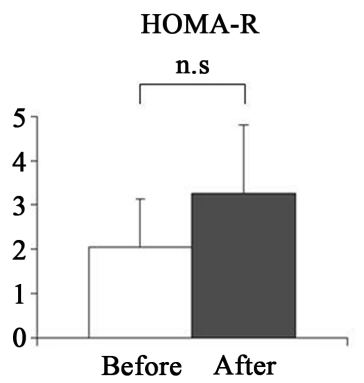

(c)
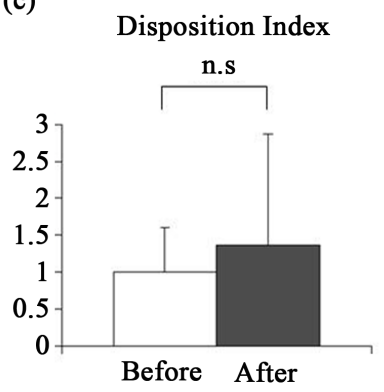

Figure 4. Did Liraglutide reduce glucose sensitivity? a-c: HOMA-R (a), Matsuda index (b), and dispositon index (c) were calculated from the result of $75 \mathrm{~g}$ oral glucose tolerance tests performed on before (open bars; $n=7$ ) and 10 days after treatment with Liraglutide (dose had been increased to $0.9 \mathrm{mg} /$ day) (closed bars; $\mathrm{n}=7$ ). ${ }^{*} \mathrm{p}<0.05 ;{ }^{* *} \mathrm{p}<0.01$ vs. before treatment assessed by paired $t$ test. Data are presented as mean (SD).

\section{Discussion}

For the treatment of diabetes with incretins, the DPP-4 inhibitor or GLP-1 receptor agonist is used. We used liraglutide to evaluate the effect of a GLP-1 receptor agonist on the improvement of $\beta$ cell function.

To determine the effect of the GLP-1 receptor agonist on improving $\beta$ cell function, an oral glucose tolerance test was performed before and after administration, and its effect was evaluated. The insulinogenic effect, represented by HOMA- $\beta$ or the AUC for insulin, was found to be improved, but improvement of the disposition index representing $\beta$ cell function was not confirmed. This result differed from a previous report that found that a low dose of liraglutide improved the disposition index [6]. One reason for this difference could be that improvement of insulin secretion was relatively poor in the early phase of the present study, as confirmed by the insulinogenic index data. It is known that early phase insulin secretion is reduced in pancreatic $\beta$ cells of diabetic patients. The decrease in the amount of pancreatic $\beta$ cells, which may have been one reason for reduction of early phase insulin secretion [9] [10], seemed to diminish the simulative effect of the GLP-1 receptor agonist on insulin's responsiveness to glucose. In our study, duration of diabetes (13.1 [SD 8.4] years) was about fourtimes compared to a previous report [6]. Because of the duration, we considered that the amount of $\beta$ cells could be less than previous report in our study, especially in Asian. In our investigation, most of participants had been poor glycemic control under previous treatment or medication, despite their endogeneous insulin secretion were certain amount. It suggested that intended diet of participants were insufficient. This insufficiency of diet was considered to be also the cause of progressive decline in $\beta$ cell function. Compared with the previous studies, the present study used oral dosing and large glucose loading (75-g). These facts may also account for differences between our results. In addition, we evaluated insulin sensitivity before and after liraglutide introduction to consider the possibility that glucose tolerance might have improved with changes in insulin sensitivity. The Matsuda index, widely known as an index to evaluate insulin sensitivity [7], was reduced. Improvement of early-phase insulin secretion may have not been adequate, and the Matsuda index was reduced as insulin secretion markedly increased at 60 minutes after glucose loading and thereafter. However, GLP-1 was reported to restore the amount of pancreatic $\beta$ cells by the proliferation of pancreatic $\beta$ cells [11], differentiation induction of pancreatic epithelial progenitor cells into $\beta$ cells [12], and the suppression of apoptosis [13] in animal experiments. Thus, a 
continued administration of GLP-1 may improve early secretion. We performed glucose tolerance tests at 6 months after the start of liraglutide therapy. Unfortunately, data investigating any further improvement of early secretion at that time were not collected. A limitation of this investigation is its short duration and small sample size. The imbalanced gender ration also might be a potential limitation of this investigation. But at least, our report is meaningful in inform that using liraglutide has a certain tendency to occur in diabetes patients. Further investigation into the effect of GLP-1 should be carried out with a large number of cases and assessment over a long period.

\section{Conclusion}

Treatment of liraglutide is likely to improve beta-cell function, but this effect probably be still inadequate in Asian type-2 diabetes patients.

\section{Transparency}

\section{Declaration of funding:}

The authors received no payment in preparation of this manuscript.

Declaration of financial/other relationships:

The authors have no significant relationships with or financial interests in any commercial companies related to study or article.

\section{Acknowledgements}

We thank all study participants for their cooperation.

\section{References}

[1] Holst, J.J. (2007) The Physiology of Glucagon-Like Peptide 1. Physiological Reviews, 87, 1409-1439. http://dx.doi.org/10.1152/physrev.00034.2006

[2] Turton, M.D., O’Shea, D., Gunn, I., Beak, S.A., Edwards, C.M., Meeran, K., et al. (1996) A Role for Glucagon-Like Peptide-1 in the Central Regulation of Feeding. Nature, 379, 69-72. http://dx.doi.org/10.1038/379069a0

[3] Wishart, J.M., Horowitz, M., Morris, H.A., Jones, K.L. and Nauck, M.A. (1998) Relation between Gastric Emptying of Glucose and Plasma Concentrations of Glucagon-Like Peptide-1. Peptides, 19, 1049-1053. http://dx.doi.org/10.1016/S0196-9781(98)00052-7

[4] Agerso, H., Jensen, L.B., Elbrond, B., Rolan, P. and Zdravkovic, M. (2002) The Pharmacokinetics, Pharmacodynamics, Safety and Tolerability of NN2211, a New Long-Acting GLP-1 Derivative, in Healthy Men. Diabetologia, 45, 195-202. http://dx.doi.org/10.1007/s00125-001-0719-z

[5] Shimoda, M., Kanda, Y., Hamamoto, S., Tawaramoto, K., Hashiramoto, M., Matsuki, M., et al. (2011) The Human Glucagon-Like Peptide-1 Analogue Liraglutide Preserves Pancreatic Beta Cells via Regulation of Cell Kinetics and Suppression of Oxidative and Endoplasmic Reticulum Stress in a Mouse Model of Diabetes. Diabetologia, 54, 10981108. http://dx.doi.org/10.1007/s00125-011-2069-9

[6] Degn, K.B., Juhl, C.B., Sturis, J., Jakobsen, G., Brock, B., Chandramouli, V., et al. (2004) One Week’s Treatment with the Long-Acting Glucagon-Like Peptide 1 Derivative Liraglutide (NN2211) Markedly Improves 24-h Glycemia and Alpha- and Beta-Cell Function and Reduces Endogenous Glucose Release in Patients with Type 2 Diabetes. Diabetes, 53, 1187-1194. http://dx.doi.org/10.2337/diabetes.53.5.1187

[7] Matsuda, M. and DeFronzo, R.A. (1999) Insulin Sensitivity Indices Obtained from Oral Glucose Tolerance Testing: Comparison with the Euglycemic Insulin Clamp. Diabetes Care, 22, 1462-1470. http://dx.doi.org/10.2337/diacare.22.9.1462

[8] Kelly, L.A., Lane, C.J., Weigensberg, M.J., Koebnick, C., Roberts, C.K., Davis, J.N., et al. (2007) Parental History and Risk of Type 2 Diabetes in Overweight Latino Adolescents: A Longitudinal Analysis. Diabetes Care, 30, $2700-2705$. http://dx.doi.org/10.2337/dc07-0050

[9] Larsen, M.O., Rolin, B., Gotfredsen, C.F., Carr, R.D. and Holst, J.J. (2004) Reduction of Beta Cell Mass: Partial Insulin Secretory Compensation from the Residual Beta Cell Population in the Nicotinamide-Streptozotocin Gottingen Minipig after Oral Glucose in Vivo and in the Perfused Pancreas. Diabetologia, 47, 1873-1878. http://dx.doi.org/10.1007/s00125-004-1546-9

[10] Butler, A.E., Janson, J., Bonner-Weir, S., Ritzel, R., Rizza, R.A. and Butler, P.C. (2003) Beta-Cell Deficit and In- 
creased Beta-Cell Apoptosis in Humans with Type 2 Diabetes. Diabetes, 52, 102-110. http://dx.doi.org/10.2337/diabetes.52.1.102

[11] Buteau, J., Foisy, S., Joly, E. and Prentki, M. (2003) Glucagon-Like Peptide 1 Induces Pancreatic Beta-Cell Proliferation via Transactivation of the Epidermal Growth Factor Receptor. Diabetes, 52, 124-132. http://dx.doi.org/10.2337/diabetes.52.1.124

[12] Friedrichsen, B.N., Neubauer, N., Lee, Y.C., Gram, V.K., Blume, N., Petersen, J.S., et al. (2006) Stimulation of Pancreatic Beta-Cell Replication by Incretins Involves Transcriptional Induction of Cyclin D1 via Multiple Signalling Pathways. Journal of Endocrinology, 188, 481-492. http://dx.doi.org/10.1677/joe.1.06160

[13] Hui, H., Nourparvar, A., Zhao, X. and Perfetti, R. (2003) Glucagon-Like Peptide-1 Inhibits Apoptosis of Insulin-Secreting Cells via a Cyclic 5'-Adenosine Monophosphate-Dependent Protein Kinase A- and a Phosphatidylinositol 3Kinase-Dependent Pathway. Endocrinology, 144, 1444-1455. http://dx.doi.org/10.1210/en.2002-220897 
Scientific Research Publishing (SCIRP) is one of the largest Open Access journal publishers. It is currently publishing more than 200 open access, online, peer-reviewed journals covering a wide range of academic disciplines. SCIRP serves the worldwide academic communities and contributes to the progress and application of science with its publication.

Other selected journals from SCIRP are listed as below. Submit your manuscript to us via either submit@scirp.org or Online Submission Portal.
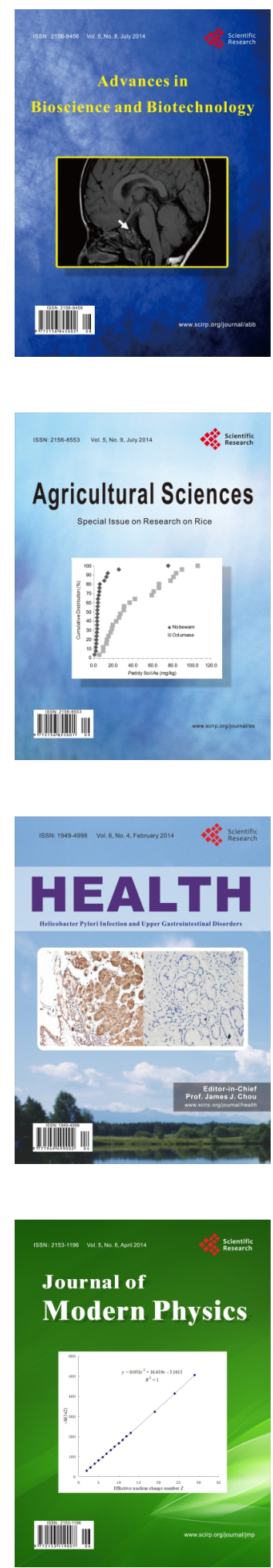
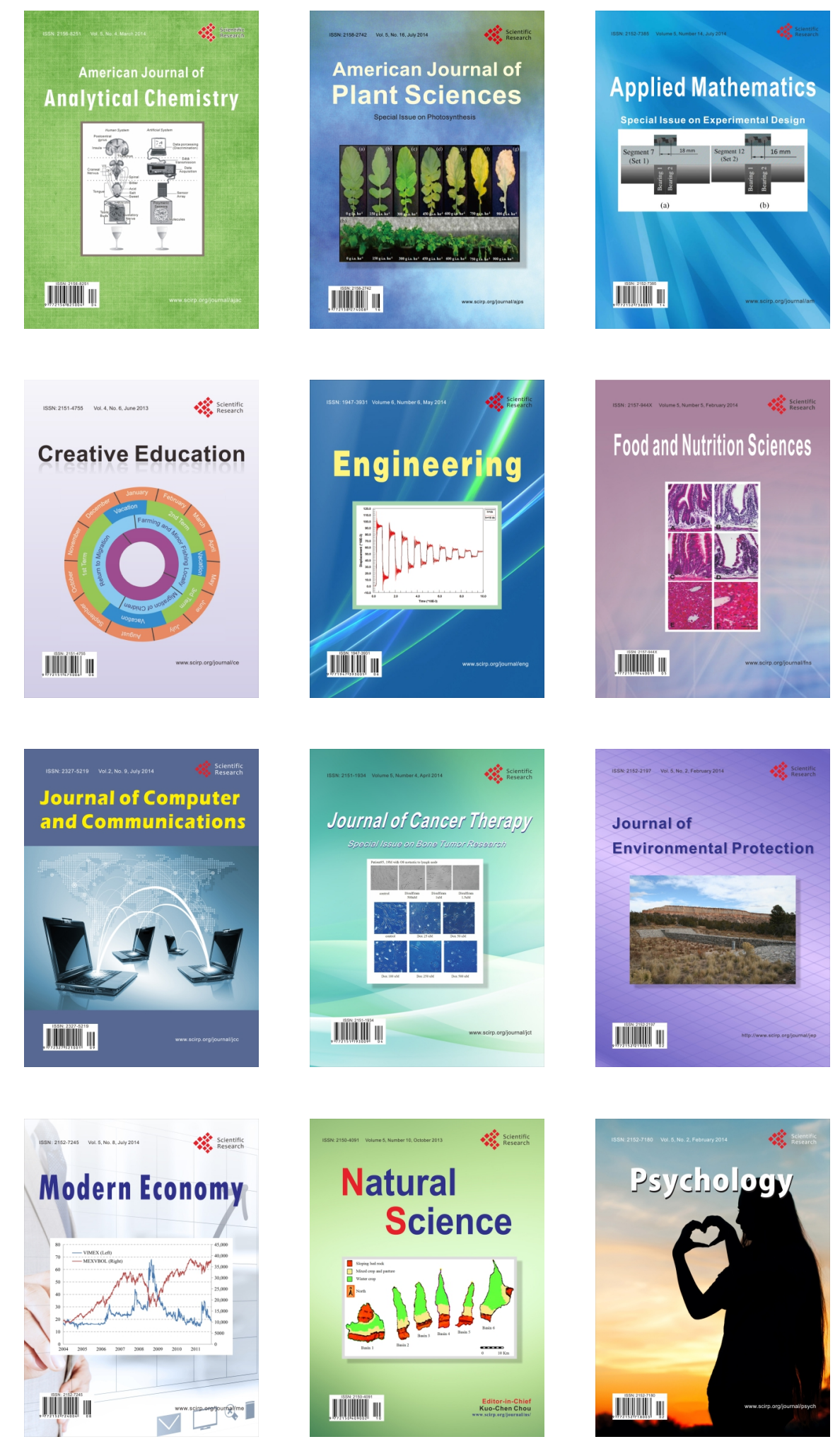